TITLE:

\title{
Measuring the efficiency of collective floodplain aquaculture of Bangladesh using Data Envelopment Analysis
}

\section{$\operatorname{AUTHOR}(\mathrm{S}):$}

Bayazid, Yamin; Umetsu, Chieko; Hamasaki, Hironori; Miyanishi, Takayuki

\section{CITATION:}

Bayazid, Yamin ... [et al]. Measuring the efficiency of collective floodplain aquaculture of Bangladesh using Data Envelopment Analysis. Aquaculture 2019, 503: 537-549

\section{ISSUE DATE:}

2019-03-30

URL:

http://hdl.handle.net/2433/253721

\section{RIGHT:}

(c) 2019. This manuscript version is made available under the CC-BY-NC-ND 4.0 license

http://creativecommons.org/licenses/by-nc-nd/4.0/.; The full-text file will be made open to the public on 30 March 2021 in accordance with publisher's 'Terms and Conditions for Self-Archiving'.; This is not the published version. Please cite only the published version.; この論文は出版社版でありません。引用の際には出版社版をご確認ご利用ください。 


\title{
Measuring the efficiency of collective floodplain aquaculture of Bangladesh
}

\section{using Data Envelopment Analysis}

\author{
Yamin Bayazid $^{\mathrm{a}^{*}}$, Chieko Umetsu ${ }^{\mathrm{b}}$, Hironori Hamasaki ${ }^{\mathrm{c}}$, Takayuki Miyanishi ${ }^{\mathrm{d}}$ \\ ${ }^{a}$ Graduate School of Fisheries and Environmental Sciences, Nagasaki University, 1-14 Bunkyo, Nagasaki \\ 852-8521, Japan; e-mail: bio_yamin@yahoo.com \\ *Corresponding author: Contact phone number: +8180 64737731 \\ ${ }^{b}$ Division of Natural Resource Economics, Graduate School of Agriculture, Kyoto University, \\ Kitashirakawa Oiwake-cho, Sakyo-ku, Kyoto 606-8502, Japan; e-mail: umetsu.chieko.5e@kyoto-u.ac.jp \\ c Graduate School of Fisheries and Environmental Sciences, Nagasaki University, 1-14 Bunkyo, Nagasaki \\ 852-8521, Japan; e-mail: h-hamasaki@nagasaki-u.ac.jp
}

dGraduate School of Fisheries and Environmental Sciences, Nagasaki University, 1-14 Bunkyo, Nagasaki 852-8521, Japan; e-mail:miyanish@nagasaki-u.ac.jp 


\section{Abstract}

This study measures efficiency of collective floodplain aquaculture enterprises (FPAs) practiced in the floodplains composed of private lands in Bangladesh using data envelopment analysis (DEA). We concentrate on a management system that was initially developed by landowners in the Daudkandi sub-district in 1984. With gradual spread of this management system two important internal variations have emerged in terms of (1) organizational composition that resulted from the investment-based participation of an NGO, and (2) mode of managing aquaculture operation that resulted from leasing out the aquaculture operation instead managing it by themselves in some FPAs. Taking consideration of these two variations, and using four inputs and one output, we measure the technical, scale, mix and overall efficiency of 15 FPAs selected from five districts. While 11 FPAs are technically efficient, only six are overall efficient. On average, NGO-collaborated FPAs (NFPAs) are more efficient $(78.27 \%)$ than landownersmanaged independent FPAs (IFPAs) (75.96\%). However, IFPAs are only found in the Daudkandi region, where there are more efficient IFPAs than NFPAs. On the other hand, while lease-based operations show better average efficiency (79.56\%), self-managed operations have more efficient units. We also find that the intensive use of inputs in most older FPAs does not make them more efficient, despite their higher fish yield, than relatively newer FPAs. Given the poverty, food security and nutrition linkage of floodplain aquaculture and continuous attempts to increase fish yield, the FPAs along with development partners and government agencies, should take account of efficiency-related aspects in policies and practice.

Keywords: efficiency measurement, floodplain aquaculture, Bangladesh, data envelopment analysis 


\section{INTRODUCTION}

Bangladesh has experienced a gradual rise in aquaculture in seasonal floodplain waterbodies in the last two decades. This trend began attracting the attention of academia and policymakers since the late 2000s (Gregory et al., 2007; Toufique and Gregory, 2008; Belton et al., 2011; Haque et al., 2011; Sultana, 2012; Joffre and Sheriff 2011; Dey et al. 2005, 2013; FRSS 2013, Bayazid, 2016), although studies have reported the simple stocking-based rise of harvested fish from floodplains since 1988-89 (Ahmed, 1999; Islam, 1999). While floodplains contain the largest area of inland waterbodies, at 2.8 million ha, only 140,000 ha of this is currently under aquaculture practice (FRSS, 2017). However, given the comparatively recent introduction of cultured practices, and that they exist in only $5 \%$ of the total floodplain area, the yield from this portion is impressive, at around $23 \%$ of the total yield from floodplain water-bodies. Thus, it has become an important sector for food security in Bangladesh.

In terms of property rights, the floodplains of Bangladesh can be divided broadly into two categories: 1) floodplains that are fully or mostly owned by various government bodies, and 2) floodplains that are primarily composed of privately-owned lands of numerous landowners. Although seasonal aquaculture is found in both categories of floodplains, the recent emergence of the trend is centered more around the second category of floodplains. A common practice to initiate and manage an aquaculture in such a floodplain is to form a collective body, mainly composed of landowners who make the necessary investment to implement aquaculture in the floodplain water-body. We use the term floodplain aquaculture (FPA) to identify this kind of collective body. In many cases, FPAs also include interested non-landowner participants, both from within and outside the community.

An early system of FPA organization and management was developed in the Daudkandi sub-district of the Comilla district when landowners of a floodplain formed an FPA named Dhanuakhola Nagarpar Adarsha Motsha Chash Prokalpo (Dhanuakhola) in 1984. However, the FPA trend gained significant momentum in this region since the formation of the FPA Pankowri 
Fisheries Ltd in 1996, where an NGO, named SHISUK ${ }^{1}$, first participated along the community participants. Through its participation, the NGO also modernized the earlier management system and demonstrated its successful application in larger water-bodies involving large number of stakeholders. Because of such role this management system was frequently associated with SHISUK in many previous studies (Gregory et al., 2007; Toufique and Gregory, 2008; Belton et al., 2011; Khan 2015; Dey et al. 2013). In any case, SHISUK gradually expanded its FPA programme by forming more NGO-collaborated FPAs (NFPAs), first in the Daudkandi region and then in other parts of the country. In the Daudkandi region, freshly motivated by the success of NFPAs, landowners of the neighbouring floodplains formed many independent FPAs (IFPAs), like Dhanuakhola, without support or involvement of any NGO or government agency. As a result of these expansions over the three decades, significant internal variations now can be observed in terms of organizational and operational aspects within the original management framework (Bayazid et al., 2018).

The purpose of this study is to measure the relative efficiency of such FPAs which, despite being formed adopting a similar management framework, now show important internal variations. In addition to measuring efficiency of aquaculture operations of these FPAs, which has not been done before, the study may indicate whether any specific variation show more efficient outcomes than others. This may shed light on relations between the FPAs' internal variations and current performances. Thus, it may also provide directions for the future improvements. Previously, a handful of studies (Mustafa and Brooks, 2009; Akter et al., 2015) compared the performance of various seasonal aquaculture enterprises, including FPAs of this management approach. However, these studies mainly compared aquaculture practices found in different kind of floodplains with different management approaches. The same is true of the study conducted by Sultana (2012), where the author compared several enclosure-based aquaculture management systems. In contrast, on one hand, we compare aquaculture practiced in the same type of water body, namely, floodplains composed of privately owned lands. On the 
other hand, the selected aquaculture enterprises are related to one another in the sense that they evolved from the same organizational and management core; that is, landowner-centred collective management. Moreover, when previous studies compared FPAs of this management framework, they ignored IFPAs and solely concentrated on NFPAs. In contrast, we try to maintain a representativeness by including FPAs of organizational and operational variations that flourished over time under a general management framework.

In addition, in this study, we introduce the data envelopment analysis (DEA) for measuring the technical, scale and mix efficiency of selected FPAs. DEA is a non-parametric approach developed by Charnes, Cooper, and Rhodes (1978) as an alternative to conventional efficiency-measurement techniques, which place some restrictions on calculating total factor productivity and are usually used to identify average, rather than the best performers. In contrast, DEA measures the relative efficiency of various entities—called decision-making units (DMUs) - engaging in the same kind of operations and provides considerable computational flexibility and ease, along with broader scope for analysis.

The application of DEA for studying the efficiency of aquaculture has become popular during the last two decades (Iliyasu et al., 2014; Sharma and Leung, 2003). Studies range from those on standard economic or technical efficiency (e.g. Sharma et al., 1999) to time series analyses (Asche et al., 2013) and combinations of DEA and other techniques (Vázquez-Rowe et al., 2010; Iliyasu et al., 2016). With regard to Bangladesh, existing DEA studies include speciesoriented analyses (Alam and Jahan, 2008; Alam, 2011), farm-based measurements (Arjumanara et al., 2004) and evaluating the potential of emerging practices (Ahmed et al., 2011).

The next section briefly introduces the organizational and management aspects of the studied FPAs. Section 3 describes the slack-based DEA methodology used in this study, and is followed by a description of the data collection process in section 4 . The results of the efficiency measurements and related analyses are presented in section 5. Section 6 concludes the paper.

\section{COLLECTIVE MANAGEMENT OF AQUACULTURE IN FLOODPLAINS}


Several types of aquaculture practices are found in the floodplains of Bangladesh and, among them, the common form consists of the rotational use of the floodplains for rice and fish production (Dey et al., 2013). In this mode, fish culture is limited to seven or eight months around the monsoon when the floodplain turns into a single water-body. In the dry season, when the individually-held plots of lands within a floodplain can be clearly demarcated, landowners usually use their lands for production of crops, predominantly rice. In the most common way of organizing such rotational rice-fish production system, privately managed rice production in the dry season is followed by collective fish culture in the monsoon season. The collective body holds the rights to conduct fish culture in the floodplain water-body during a stipulated period around the monsoon.

The selected FPAs are one type of such collective body. In terms of organization, the common features of these FPAs are that (1) they are mainly composed of landowners of the floodplains, and (2) the basic contribution that all participants must make is to invest to initiate fish culture operation. When non-landowners from the community-who do not own any land in the cultured floodplain and are more common in NFPAs-participate in FPAs, they also have to make such investment to create the basis of their participation. This is also true for the extracommunity non-governmental organization (NGO), SHISUK - the only one that is found as a participant in some FPAs_-since, like all other landowner and non-landowner participants, SHISUK also invested in the FPA shares. An FPA formed this way holds the collective rights to fish culture operation and, usually pay land rent ${ }^{2}$ to each landowner in exchange of transferring their private property rights to the FPA.

It should be noted that, the initial involvement of SHISUK mainly resulted from its role in promoting FPAs in the related communities. Although the inclusion of such non-landowner and involvement of NGOs are not uncommon in other floodplain aquaculture systems, their modes of involvement are varied in different management systems ((Dey et al. 2003 \& 2005; Joffre et al. 2011). In our study, we concentrate on the management system where participation 
NGO participates by making investment like all other participants. To the best of our knowledge, SHISUK is the only NGO who participated in this manner.

In terms of management, each FPA forms a management committee from its shareholders to make decisions about and oversee all kinds of FPA functions, including fish culture operations. In NFPAs, SHISUK also acts as a member of the management committee. Such a management committee holds the sole rights over the harvesting of fish and no shareholder is permanent to harvest from the cultured water-body. The operational pattern of fish farming followed by these management committees are almost identical, since all FPAs conducted culture activities around the monsoon in same type of floodplains. This process is presented in Figure 1. Some infrastructural development or modification of the floodplain under aquaculture has been made before the inception of an FPA enterprise. This includes the construction of permanent earthen embankments and roads along the borders of the floodplain to control the flow of water and to transport inputs and outputs. After these preliminary steps are completed, the fish farming process follows the usual pattern of stocking, nurturing and harvesting (Figure 1). After harvesting net return or profit was distributed among shareholders as dividends and as land rent among landowners.

However, despite following a similar approach for organizing and managing their activities, some important variations can also be found among these FPAs that have emerged

\section{Harvesting: After the monsoon, water} is retained by the means of earthen enclosure or in perennial marshy part of the floodplain until November/December for harvesting.

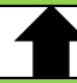

Nurturing: In late June/early July monsoon rain inundates the floodplain. Stocked fish spread to the whole floodplain and are nurtured till harvest.
Dry season activity: After the enclosed area of the floodplain is drained following aquaculture phase, landowners use their lands for crop production during December to June.

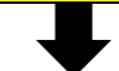

Stocking: During pre-monsoon months of March/April, the perennial, marshy lower part of floodplains are stocked with fingerling.

Figure 1: Annual cycle of aquaculture and agriculture in floodplain (adapted from Bayazid 2016, p862) 
over the years. In a previous study Bayazid et al. (2018) mentioned of two most important variations. First, with respect to organizational composition, we already mentioned the most obvious types, namely NFPAs and IFPA, that resulted from the involvement of the NGO, SHISUK, as an important stakeholder in some FPAs.

Second type of variation is found in terms of the mode of managing aquaculture operations. Typically, the management committee of an FPA oversee all aspects of aquaculture operations and make related decisions. However, in some FPAs, a lease-based management of aquaculture operation has been developed. In lease-based management, the FPA's management committee, as the representative of investors, transfers their rights of managing the aquaculture operation to a group of lessees in exchange for a transfer fee. The aquaculture operation is usually leased for more than one season (e.g. for two to three years). It is worth mentioning that the lease-based mechanism was developed as a solution to the persistently low performance or losses in some FPAs. Today, many FPAs (both IFPAs and NFPAs) have adopted the leasemanaged mechanism, while others continue a self-managed operation. In this study, in addition to measuring efficiency of FPAs of this management system, we try to see whether (1) the involvement of NGO have any positive impact on efficiency, and (2) lease-based operations are more efficient than self-managed operations.

\section{METHODOLOGY: DATA ENVELOPMENT ANALYSIS}

DEA is used to measure the efficiency of target DMUs by establishing a frontier surface that contains the efficient DMUs and envelops the inefficient one (Cooper et al., 2007) through mathematical and linear programming. Inspired by Farrell's seminal work (1957), Charnes et al. $(1978,1981)$ developed the first DEA model, known as the CCR (Charnes-Cooper-Rhodes), to consider total factor productivity by including multiple inputs and outputs into an efficiency calculation. DEA identifies the best DMUs and measures the relative efficiency of others with reference to the best ones. In this study, to draw a comprehensive picture of efficiency of FPAs, 
we use three DEA models, namely CCR, Banker-Charnes-Cooper (BCC) and slack-based measure (SBM), which are briefly described as follows.

The CCR model for measuring technical efficiency: Technical efficiency (TE) measures the extent to which a DMU produces the maximum feasible output from a given set of inputs, or uses the minimum level of inputs to produce a given level of output. The most common DEA model that is used to measure TE is CCR. The usual linear programming (LP) formula for measuring CCR efficiency $\theta$ is as follows:

$$
\begin{aligned}
& \left(C C R_{L P}\right) \max _{v, u} \theta=u y_{o} \\
& \text { subject to } v x_{o}=1 \\
& v X \geq u Y \\
& u \geq 0, v \geq 0 .
\end{aligned}
$$

where $x_{0}$ and $y_{0}$ are the input vector and output vector, respectively, and $v$ and $u$ represent vectors of input weights and output weights. The constraints are set such that the value of $\theta$ ranges from 0 to 1 . If the objective value $\theta^{*}$ is 1 for the target $\mathrm{DMU}$, then it is efficient, otherwise it is inefficient. The CCR score shows the input minimization rate in an input-oriented model, or the output augmentation rate in an output-oriented model. Figure 2 shows a simple representation of the CCR frontier as a straight line from the origin for eight DMUs with one input and one output. Here, $\mathrm{H}$ is the only efficient DMU, since it is located on the CCR frontier. It is the failure to reach the frontier that makes other DMUs inefficient..The CCR model assumes a technology which is operating at constant returns to scale (CRS). Thus, in a CCR model, consideration of the best performance in terms of returns to scale (RTS) is already embedded, and CCR-efficient DMUs are also scale efficient (Coelli et al., 2005).

Variable returns to scale and the BCC model: To incorporate variable returns to scale (VRS) characteristic of the production technology, Banker et al. (1984) proposed the BCC model by 
separating the simultaneous measurement of technical and scale efficiencies in the CCR model.

This model which produces pure technical efficiency (PTE) can be represented as follows:

$$
\begin{aligned}
& \left(B C C_{D}\right) \max _{v, u} \theta_{B}=u y_{o}-u_{0} \\
& \text { subject to } v x_{o}=1 \\
& v X \geq u Y-u_{0} \\
& u \geq 0, v \geq 0 \text {, where } u_{0} \text { free of sign. }
\end{aligned}
$$

Here, $u_{0}$ can be used to identity the RTS nature of the DMUs, that is, whether they are increasing returns to scale (IRS), decreasing returns to scale (DRS), or constant returns to scale (CRS). The BCC frontier is piece-wise linear as shown in the dashed connected lines of Figure 2. While, as in the CCR model, the BCC score ranges from 0 to 1 , the BCC frontier contains more efficient DMUs than the CCR frontier because of former's VRS assumption.

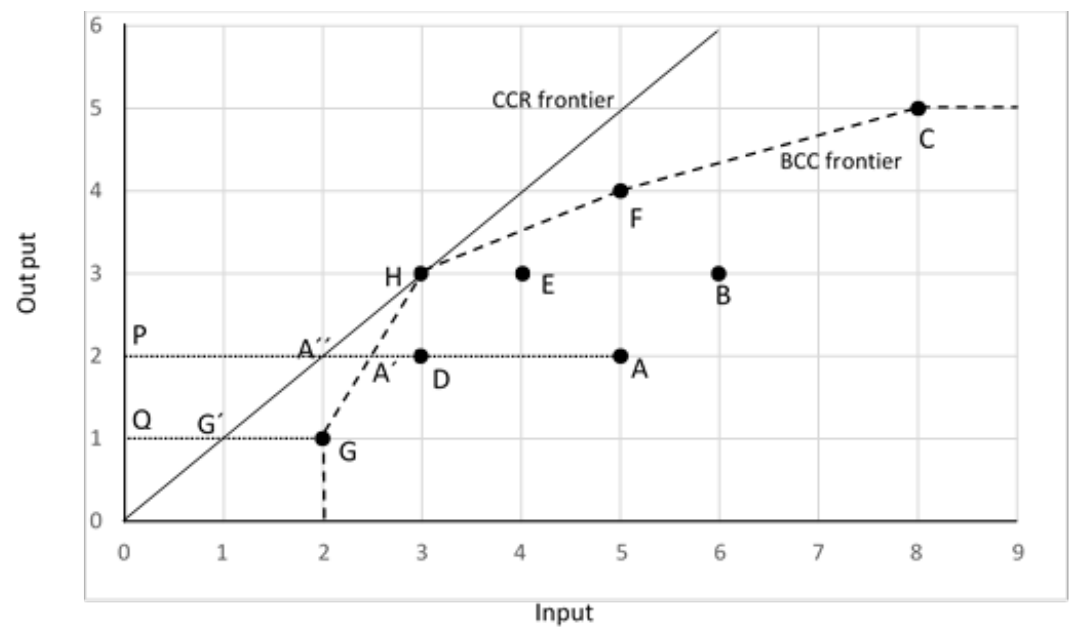

Figure 2: CCR and BCC frontiers

Scale efficiency from CCR and BCC scores: Scale efficiency (SE) measures whether a DMU performs at the optimal scale level. Because of the separation of the technical and scale aspects of efficiency, SE of a DMU can be calculated as the ratio of its CCR efficiency $\left(\mathrm{CCR}_{\theta}\right)$ to its BCC efficiency $\left(\mathrm{BCC}_{\theta}\right)$ :

$$
S E=C C R_{\theta} / B C C_{\theta}
$$


Like CCR and BCC, the SE score cannot be greater than 1. A DMU can be efficient in terms of PTE by being BCC-efficient but not CCR-efficient because of its scale inefficiency. Because of this, CCR-efficiency is also known as global TE.

Slack-based measure (SBM) and mix efficiency: When DMUs use multiple inputs (or produce multiple outputs) in a mix, like the example in Figure 3 with two inputs for one output, inefficiency can originate from the way they are mixed. CCR and BCC do not directly calculate such mix or non-radial inefficiency, even though a technically (radial) efficient DMU may use excessive inputs or have output shortfall. For example, in Figure 3, U can be technically efficient by reaching U', but can reach T only by removing excess input. Such excesses or shortfalls are known as slacks and can be measured by several DEA models. In our study, we use the SBM for non-radial efficiency (Tone, 2001). The SBM model can be defined as follows:

$$
\begin{aligned}
& (\mathrm{SBM}) \min _{\lambda, s^{-}, s^{+}} \rho=\frac{1-\frac{1}{m} \sum_{i=1}^{m} s_{i}^{-} / x_{i o}}{1+\frac{1}{s} \sum_{r=1}^{s} s_{r}^{+} / y_{r o}} \\
& \text { Subject to } x_{o}=X \lambda+s^{-} \\
& y_{o}=Y \lambda-s^{+} \\
& \lambda \geq 0, \mathrm{~s}^{-} \geq 0, \mathrm{~s}^{+} \geq 0
\end{aligned}
$$

Like CCR and BCC efficiency, the SBM efficiency score $\rho^{*}$ ranges from 0 to 1 . When a DMU has no input slacks $\left(s^{-}\right)$and/or output slacks $\left(s^{+}\right)$, then the DMU has an efficiency score of 1.

Moreover, SBM scores incorporate the mix efficiency (ME) with CCR efficiency. Thus, ME can be measured as,

$$
M E=S B M_{\rho} / C C R_{\theta}
$$

where $S B M_{\rho}$ is the slack-based efficiency score and $C C R_{\theta}$ is the CCR efficiency score. From this we can derive

$$
\begin{aligned}
& S B M_{\rho}=M E \times C C R_{\theta}, \text { and from (5) } \\
& S B M_{\rho}=M E \times S E \times B C C_{\theta} .
\end{aligned}
$$




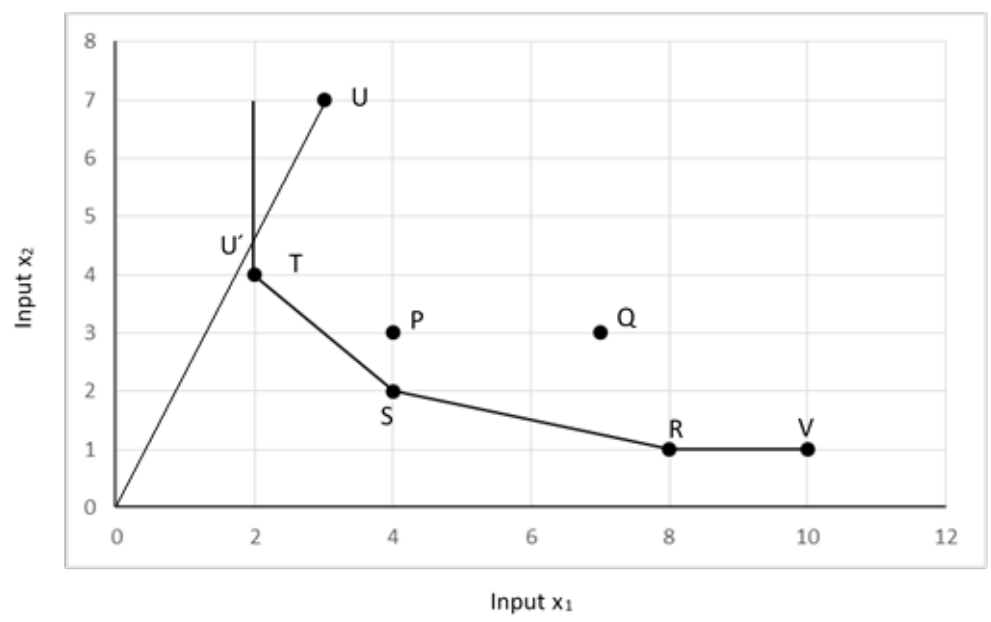

Figure 3: Mix Efficiency

Thus, SBM can be decomposed conveniently into the measurement of ME, SE and PTE and be used as an indicator of overall efficiency.

\section{DATA, AND INPUT AND OUTPUT SPECIFICATIONS}

For measuring the efficiency of FPAs with the focused management system, we selected 15 FPAs from five sub-districts of Bangladesh. They are the Daudkandi (Comilla district), Harirampur (Manikganj district), Shingra (Natore district), Rajapur (Jhalokati district) and Nazirpur (Pirojpur district) sub-districts. While the Daudkandi region has well established association with this management system, selection of the other sites was based upon the presence of NFPA in a community. This is because the NGO has been engaged in introducing this management system in different parts of the country since 2010s. At the time of this study, NFPAs were found in seven sub-districts, including Daudkandi. Of these, five were selected where at least one continuously operational FPA was found.

Although we attempted to select both NFPAs and IFPAs from all sites to maintain representativeness, outside Daudkandi, this management system is relatively new. Thus, while more than 50 FPAs (numerous IFPAs and six NFPAs) are reported to be operational in and around the Daudkandi sub-district, in the other four sites only NFPAs are found to perform continuously using a well-organized institutional scheme. As a result, 11 FPAs (six NFPAs and 
five IFPAs) were selected from the Daudkandi region, and one NFPA from each of the other four sub-districts was selected based on the information provided by the NGO.

In the Daudkandi region, with the help of field level NGO staff, contacts with NFPAs were established and all six operational NFPAs were surveyed. Later, the assistance of NGO staff was also taken in identifying and selecting IFPAs from this region. Such assistance was sought after for several reasons. First, there is a lack of any comprehensive and up to date database of the operational FPAs in this region. The government database was old and unreliable. Second, given the fact that the local NGO staff maintain relations with other FPAs, it was assumed that the IFPA respondents would feel more comfortable about the surveys and thus be confident and ready to share information, if they were approached by the NGO staff. From the surveyed IFPAs, five were selected from which complete relevant data was able to be collected.

In Table 1, 15 selected FPAs are listed chronologically by year of formation, along with their shortened names in the parentheses which are used in this paper for the sake of convenience. In final sample, we tried to include at least more than one FPA of each variation described in section 2. We included 10 NFPAs and five IFPAs. In terms of mode of managing aquaculture operations seven FPAs followed self-management, eight lease-based management. While all NFPAs from the Daudkandi region have adopted lease-based management of aquaculture, those from other four sites reminded under self-management. Among the five IFPAs, found only from the Daudkandi region, three followed self-managed, while the other two adopted lease-based aquaculture operations.

Fish production data of the FPAs were collected from their official account records for the year 2015-16 by conducting two field visits during April-May and October-November of 2016 in the five selected sites. An FPA-specific questionnaire was developed for data collection, supplemented by non-structured questions, which were asked as needed during the field visits. 
Table 1 shows the four inputs and one output that are included in efficiency measurement of selected FPAs. Inputs were primarily selected on the basic of their share in total cost. Most cost-incurred items are fish feed, fingerlings and salaries and wages paid to the regular and non-regular workforce. All FPAs also use some common type of fertilizers to grow natural fish feed, along with lime, and other chemical products, like medicines for fish diseases, etc. These are bundled together with usual fish feed in 'feed and others'. These three inputs are measured in monetary units of Bangladeshi Taka (BDT; BDT 80.50=US\$1). On average, they together incurred more than $80 \%$ of total cost of the FPAs, while, individually, feed and others $48 \%$, fingerlings $18 \%$ and wages and salaries $18 \%$. In addition to these inputs, to consider the contribution of land in fish culture, utilized area of floodplain (UAF) within which an aquaculture operation is confined is considered as an input ${ }^{3}$. In all FPAs, the selected inputs are standard inputs.

Other important outlays for the FPAs include the repair and maintenance of the aquaculture related infrastructures built in and around the utilized area of floodplain, as well as compensation paid to neighbouring households for damages caused by the aquaculture operations. However, a large portion of such expenses is the result of the floodplain's geographical features, rather than the capability of the management. At the same time, although important in terms of aquaculture operations, these items individually incurred very small portion of total cost. For example, for repair and maintenance of infrastructure the FPAs expended, on average, $1 \%$ of total cost. Thus, we do not consider such outlays as inputs.

Fish sales in BDT are considered as the single output of the FPAs. All FPAs were found to follow the strategy of 'commoditized bulk production' (Hernandez et al., 2017) by culturing an almost identical mix of fish species, dominated by carp along with some introduced species, like tilapia. The relatively newer FPAs harvested some naturally recruited fish. However, in comparison to stocked fish, their contribution to sales revenue is very small and no additional feed or other input was supplied for them. 
Under the lease-based management, the lessee-group manages the aquaculture operation in the same fashion as that the management committee of an FPA does. Moreover, the collective rights over the aquaculture operation in the relevant floodplain ultimately belong to the FPA which leases its rights to the lessees for a specified period. Thus, even though the lessee-group manages the aquaculture mostly independent from the FPA's management committee, we subsume lessee-managed operation within the boundary of the FPA. Finally, even when the aquaculture operation is leased, the FPA's management committee remains responsible for the repair and maintenance of the infrastructure. It finances such expenditures from the payment it receives from the lessees. The rest of the lease payment is used to meet administrative expenses. The residual amount is distributed as a return among the investor-members of the FPA, and as land rent to the landowners. However, as is the usual practice, the land rent is paid only after paying all other expenses. Thus, the rationale for not including the land rent as an input or an output remains valid for FPAs which adopted lease-based operation. 
Table 1: Information of studied FPAs

\begin{tabular}{|c|c|c|c|c|c|c|c|c|}
\hline & \multirow{2}{*}{ FPA Name } & \multirow{2}{*}{$\begin{array}{l}\text { Year of } \\
\text { formation }\end{array}$} & \multirow[t]{2}{*}{ Location } & \multicolumn{4}{|c|}{ Inputs } & \multirow{2}{*}{$\begin{array}{c}\text { Output } \\
\text { Fish sales } \\
\text { (Million } \\
\text { BDT) }\end{array}$} \\
\hline & & & & $\begin{array}{l}\text { UAF* } \\
\text { (ha) }\end{array}$ & $\begin{array}{c}\text { Fingerling } \\
\text { (Million } \\
\text { BDT) }\end{array}$ & $\begin{array}{l}\text { Feed \& } \\
\text { others } \\
\text { (Million } \\
\text { BDT) }\end{array}$ & $\begin{array}{l}\text { Salaries } \\
\text { (Million } \\
\text { BDT) }\end{array}$ & \\
\hline 1. & $\begin{array}{l}\text { Dhanua Khola Nagarpar Adarsha Motsha } \\
\text { Chash Prokalpo (Dhanuakhola) }\end{array}$ & 1984 & $\begin{array}{l}\text { Daudkandi, } \\
\text { Comilla }\end{array}$ & 13.23 & 1.767 & 4.287 & 0.328 & 8.174 \\
\hline 2. & Pankowri Fisheries Ltd. (Pankowri) & 1996 & $\begin{array}{l}\text { Daudkandi, } \\
\text { Comilla }\end{array}$ & 85 & 6.265 & 17.698 & 3.751 & 37.835 \\
\hline 3. & Charipara Rupali Agro-fisheries (Charipara) & 1999 & $\begin{array}{l}\text { Daudkandi, } \\
\text { Comilla }\end{array}$ & 26.71 & 1.906 & 5.933 & 1.291 & 10.584 \\
\hline 4. & Kushiara Fisheries (Kushiara) & 2000 & $\begin{array}{l}\text { Daudkandi, } \\
\text { Comilla }\end{array}$ & 13.35 & 1.387 & 15.598 & 3.633 & 25.849 \\
\hline 5. & Asia Fisheries (Asia) & 2001 & $\begin{array}{l}\text { Daudkandi, } \\
\text { Comilla }\end{array}$ & 170 & 7.709 & 15.125 & 5.638 & 35.206 \\
\hline 6. & Khirai Fisheries Ltd. (Khirai) & 2003 & $\begin{array}{l}\text { Daudkandi, } \\
\text { Comilla }\end{array}$ & 61 & 3.048 & 13.040 & 3.605 & 23.638 \\
\hline 7. & LKS Fisheries Ltd. (LKS) & 2003 & $\begin{array}{l}\text { Daudkandi, } \\
\text { Comilla }\end{array}$ & 46.94 & 1.214 & 8.477 & 2.601 & 13.736 \\
\hline
\end{tabular}


8. Chargram Fisheries Ltd. (Chargram)

9. Shishir Motsha Chash Prokolpa (Shishir)

10. Proshanto Motsho Prokalpo (Proshanto)

11. Shanto Motsho Prokalpo (Shanto)

12. DKK Bio-Village O Samajik Motsho Prokolpo (DKK)

13. Raninagar Chalan Beel Motsho Community Enterprise (Raninagar)

14. Uttompur Badurtola Motsho Chash Community Enterprise (Uttompur)

15. Jhonjhonia SHISUK Community Enterprise (Jhonjhonia)

\begin{tabular}{|c|c|c|c|c|c|c|}
\hline \multirow{2}{*}{2004} & Daudkandi, & 140 & 3.018 & 12.858 & 4.874 & 32.304 \\
\hline & Comilla & & & & & \\
\hline \multirow[t]{2}{*}{2004} & Daudkandi, & 13.35 & 0.994 & 5.377 & 1.329 & 6.668 \\
\hline & Comilla & & & & & \\
\hline \multirow[t]{2}{*}{2007} & Daudkandi, & 147 & 4.165 & 14.002 & 4.723 & 33.058 \\
\hline & Comilla & & & & & \\
\hline \multirow[t]{2}{*}{2007} & Daudkandi, & 80.13 & 2.117 & 11.189 & 3.642 & 26.725 \\
\hline & Comilla & & & & & \\
\hline \multirow[t]{2}{*}{2012} & Harirampur, & 54.54 & 0.207 & 1.081 & 0.956 & 2.925 \\
\hline & Manikganj & & & & & \\
\hline 2013 & Singra, Natore & 25 & 1.091 & 1.685 & 0.386 & 5.934 \\
\hline \multirow[t]{2}{*}{2015} & Rajapur, & 28.04 & 0.050 & 0.101 & 0.084 & 0.150 \\
\hline & Jhalokati & & & & & \\
\hline \multirow[t]{6}{*}{2015} & Nazirpur, & 37.39 & 0.726 & 0.023 & 0.206 & 1.465 \\
\hline & Pirozpur & & & & & \\
\hline & & 62.78 & 2.3776 & 8.4315 & 2.4697 & 17.6167 \\
\hline & & 170 & 7.7089 & 17.698 & 5.6379 & 37.8353 \\
\hline & & 13.23 & 0.0495 & 0.0225 & 0.0844 & 0.14957 \\
\hline & & 50.06 & 2.1137 & 5.9660 & 1.8490 & 13.0413 \\
\hline
\end{tabular}




\section{RESULTS AND DISCUSSION}

\subsection{Input-oriented efficiency scores of FPAs}

The input-oriented DEA analysis is shown in Table 2. It contains five types of efficiency scores: pure or local technical (BCC-I), scale of operation (SE-I), global technical (CCR-I), input mix (ME-I), and overall efficiency (SBM-I). Among the 15 studied FPAs, six are overall efficient. The scores are discussed in detail as follows.

BCC, SE and CCR performances: The average BCC-I score is 0.96, with 11 efficient FPAs. This suggests that most of the FPAs are performing well in terms of achieving pure technical potential. Among the BCC-I inefficient FPAs, Proshanto is very close to the efficient score of 1, while LKS has the lowest BCC score. Three FPAs scored below the mean BCC-I score.

However, considering the CCR-I results (with an average of $89 \%$ efficiency score), we found that a few FPAs (like Uttompur and Shishir), that are BCC-efficient, have very poor CCR scores. The BCC-efficiency of Uttompur may be due to its utilization of the least amount of inputs (e.g. fingerling, etc.). Among the CCR-I inefficient FPAs, six scored lower than the mean. We have already learned that the difference between the CCR and BCC scores originated from scale efficiency. The scale efficiency scores of the FPAs that are BCC-efficient, but not CCRefficient, are the same as their CCR-I scores. Therefore, these FPAs can become CCR-efficient by removing scale inefficiency. Using the returns to scale characteristics of the FPAs, derived from the BCC-I calculations, it can be suggested that Pankowri, Asia, and Chargram can decrease the size of their operations, while Shishir and Uttompur (which have the lowest scale and technical efficiency scores) can increase the size of their operations to become scale and technical efficient. On average, the FPAs are 91\% scale efficient, with four FPAs showing below-average scores. This suggests that, on average, the FPAs are more efficient in pure technical performances than they are in terms of scale performance. This is usual, given the BCC 
model's scale-flexible assumptions. Charipara, Khirai, LKS, and Proshanto are inefficient in both pure and global technical categories. It can be seen from Table 2 that, except for Proshanto, other three have better scale optimization than technical performances. This implies that to improve their efficiency they should concentrate on management and operational efficiency, while Proshanto needs to focus on the size of its operations.

Overall (SBM-I) and mix (ME) efficiency: In keeping with DEA principles, the average of SBM-I scores are the lowest (77\%) among all types of efficiency scores, because to calculate overall efficiency SBM-I scores combine other efficiency scores (Table 2). Of the nine overall inefficient FPAs, seven scored lower than the mean SBM-I score. Here, Uttompur has the lowest score.

On one hand, the SBM-I scores reflect the presence of slacks in inputs and measure the slacks that should be eradicated by inefficient FPAs to reach the efficient frontier. Table 3 shows the required percentage decrease of each input obtained from the SBM-I model. As expected, FPAs with the lowest SBM-I scores had the highest percentage of slacks to decrease. Table 3 shows that the FPAs have the largest amount of slacks in land use. Interestingly, land is also the most difficult input to decrease, given the infrastructures developed around the UAF. Large amount of the slacks in UAF indicates that the FPAs can achieve the same level of fish production with considerably less land. Next to UAF, stocked fingerling and wages and salaries (paid against labour and staff) have the largest slacks. Although, feed is the largest input in monetary terms in most FPAs, it has the smallest amount of slacks.

On the other hand, SBM-I scores can be decomposed, primarily into technical (CCR-I) and mix (ME-I) efficiency scores. Using (5), we obtained mix efficiency scores of the FPAs with an average of $89.83 \%$ (Table 2). Here, six FPAs had lower than average scores. Among the overall inefficient FPAs, some (Charipara, Asia, Shishir, Proshanto and Uttompur) have lower technical efficiency scores than mix efficiency scores, while others (Pankowri, Khirai, LKS, and 
Chargram) have lower mix efficiency scores. Thus, these FPAs can focus accordingly to improve their overall efficiency.

Finally, from (6), the scores of the nine overall (SBM) inefficient FPAs can be decomposed into their technical (BCC), scale (SE), and mix (ME) sources. This is shown in Figure 4, along with the mean BBC-I, SE-I, and ME-I scores. This figure shows that while many FPAs performed well in pure technical terms (panel A), their relatively low scale and mix efficiency scores contributed to their overall inefficiency which resulted in poor SBM-I scores (panel D). Furthermore, the figure shows that of the nine inefficient FPAs, six have above average scale efficiency scores and three (Pankowri, Charipara, and Chargram) were very close to being efficient (panel B). However, in the case of the mix efficiency scores (panel C), only three FPAs have above average scores and none of them are close to an efficiency score of one. This implies that, most inefficient FPAs fare better in maintaining the size of their aquaculture operations than balancing a commensurate mix of the inputs to run those operations. 
Table 2: Input-oriented efficiency scores of the FPAs

\begin{tabular}{|c|c|c|c|c|c|c|c|c|}
\hline FPAs & $\begin{array}{l}\text { Organization } \\
\text { composition }\end{array}$ & $\begin{array}{l}\text { Mode of } \\
\text { aquaculture } \\
\text { operation }\end{array}$ & RTS & BCC-I & SE-I & CCR-I & ME-I & SBM-I \\
\hline Dhanuakhola & IFPA & Lease-managed & CRS & 1 & 1 & 1 & 1 & 1 \\
\hline Pankowri & NFPA & Lease-managed & DRS & 1 & 0.9818 & 0.9818 & 0.9388 & 0.9217 \\
\hline Charipara & IFPA & Self-managed & DRS & 0.8348 & 0.9992 & 0.8341 & 0.8628 & 0.7197 \\
\hline Kushiara & IFPA & Self-managed & CRS & 1 & 1 & 1 & 1 & 1 \\
\hline Asia & IFPA & Self-managed & DRS & 1 & 0.7652 & 0.7652 & 0.8866 & 0.6784 \\
\hline Khirai & NFPA & Lease-managed & DRS & 0.8559 & 0.9800 & 0.8388 & 0.8506 & 0.7135 \\
\hline LKS & NFPA & Lease-managed & IRS & 0.8106 & 0.9695 & 0.7859 & 0.7885 & 0.6197 \\
\hline Chargram & NFPA & Lease-managed & DRS & 1 & 0.9960 & 0.9960 & 0.9436 & 0.9398 \\
\hline Shishir & IFPA & Lease-managed & IRS & 1 & 0.6617 & 0.6617 & 0.7825 & 0.5178 \\
\hline Proshanto & NFPA & Lease-managed & DRS & 0.9753 & 0.9076 & 0.8852 & 0.9144 & 0.8094 \\
\hline Shanto & NFPA & Lease-managed & CRS & 1 & 1 & 1 & 1 & 1 \\
\hline DKK & NFPA & Self-managed & CRS & 1 & 1 & 1 & 1 & 1 \\
\hline Raninagar & NFPA & Self-managed & CRS & 1 & 1 & 1 & 1 & 1 \\
\hline Uttompur & NFPA & Self-managed & IRS & 1 & 0.4517 & 0.4517 & 0.6159 & 0.2782 \\
\hline Jhonjhonia & NFPA & Self-managed & CRS & 1 & 1 & 1 & 1 & 1 \\
\hline Geometric Mean & & & & 0.9626 & 0.8960 & 0.8626 & 0.8983 & 0.7749 \\
\hline Maximum & & & & 1 & 1 & 1 & 1 & 1 \\
\hline Minimum & & & & 0.8106 & 0.4517 & 0.4517 & 0.6159 & 0.2782 \\
\hline Standard deviation & & & & 0.0688 & 0.1626 & 0.1619 & 0.1115 & 0.2212 \\
\hline
\end{tabular}


Table 3: Input slacks of the FPA operation from SBM-I scores (required percentage decrease of each inputs is shown in brackets)

\begin{tabular}{|c|c|c|c|c|}
\hline FPAs & $\begin{array}{l}\text { UAF } \\
\text { (ha) }\end{array}$ & $\begin{array}{l}\text { Fingerling } \\
\text { (Million BDT) }\end{array}$ & $\begin{array}{l}\text { Feed \& others } \\
\text { (Million BDT) }\end{array}$ & $\begin{array}{l}\text { Wage and salaries } \\
\text { (Million BDT) }\end{array}$ \\
\hline Dhanuakhola & 0 & 0 & 0 & 0 \\
\hline Pankowri & $5.245(6.17 \%)$ & $1.577(25.16 \%)$ & 0 & 0 \\
\hline Charipara & $15.784(59.09 \%)$ & $1.01(53.02 \%)$ & 0 & 0 \\
\hline Kushiara & 0 & 0 & 0 & 0 \\
\hline Asia & $81(47.64 \%)$ & $3.32(43.12 \%)$ & 0 & $2.13(37.87 \%)$ \\
\hline Khirai & $34.62(56.75 \%)$ & $1.28(41.99 \%)$ & 0 & $0.57(15.85 \%)$ \\
\hline LKS & $39.84(84.88 \%)$ & $0.48(39.26 \%)$ & $0.19(2.21 \%)$ & $0.67(25.76 \%)$ \\
\hline Chargram & $17.91(12.79 \%)$ & 0 & 0 & $0.55(11.28 \%)$ \\
\hline Shishir & $9.90(74.20 \%)$ & $0.64(64.00 \%)$ & $1.35(25.16 \%)$ & $0.39(29.49 \%)$ \\
\hline Proshanto & $50.06(34.05 \%)$ & $1.57(37.67 \%)$ & 0 & $0.21(4.53 \%)$ \\
\hline Shanto & 0 & 0 & 0 & 0 \\
\hline DKK & 0 & 0 & 0 & 0 \\
\hline Raninagar & 0 & 0 & 0 & 0 \\
\hline Uttompur & $27.41(97.75 \%)$ & $0.02(44.52 \%)$ & $0.06(57.96 \%)$ & $0.075(88.46 \%)$ \\
\hline Jhonjhonia & 0 & 0 & 0 & 0 \\
\hline
\end{tabular}

\begin{tabular}{lllll}
\hline Mean & $18.79(31.57 \%)$ & $0.66(23.52 \%)$ & $0.11(5.69 \%)$ & $0.31(14.22 \%)$
\end{tabular}




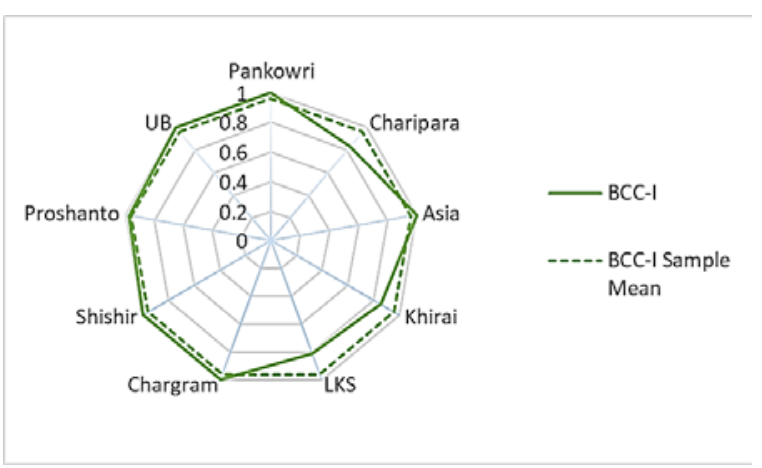

Panel A. BCC-I

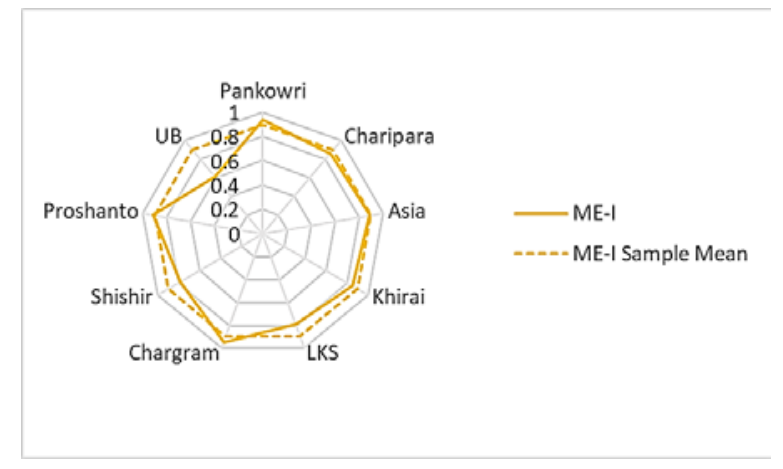

Panel C. ME-I

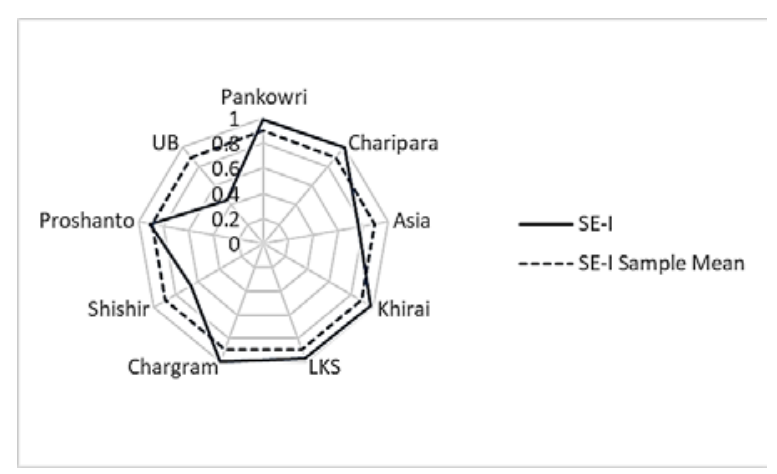

Panel B. SE-I

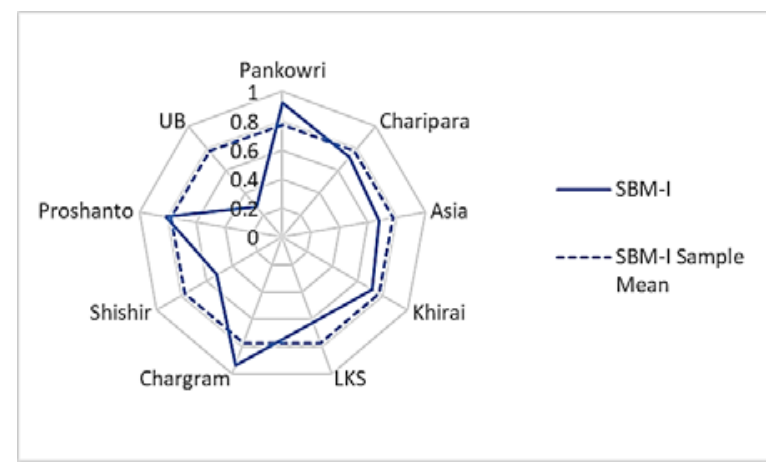

Panel D. SBM-I

Figure 4: Decomposition of SBM-I scores of inefficient FPAs into BCC-I, SE-I and ME-I scores (broken lines indicate mean score of each category of DEA results)

The returns to scale features of the FPAs are shown in Figure 5. All six CCR-efficient FPAs—also overall efficient—show constant returns to scale characteristics (as per DEA principles). Among the inefficient FPAs, six showed decreasing returns to scale and three increasing returns to scale characteristics. This means that most of the inefficient FPAs are performing at a supra-optimal scale. On the other hand, the increasing returns to scale characters of three FPAs, that also have the lowest overall efficiency scores, suggest that they are performing at a sub-optimal level.

If we consider the utilized land area (UAF) of each FPA as an indicator of its size, then we can see that FPAs with decreasing returns to scale have the highest mean UAF in comparison with the FPAs showing constant and increasing returns to scale. This is shown in Figure 6, along with the sample mean of the UAF. This simply indicates that, among the inefficient FPAs, the number of relatively larger FPAs is higher than the number of smaller FPAs. Indeed, out of the 
six overall efficient FPAs, only Shanto has more UAF than the sample average. Note that there are five FPAs with a higher UAF than the sample mean.

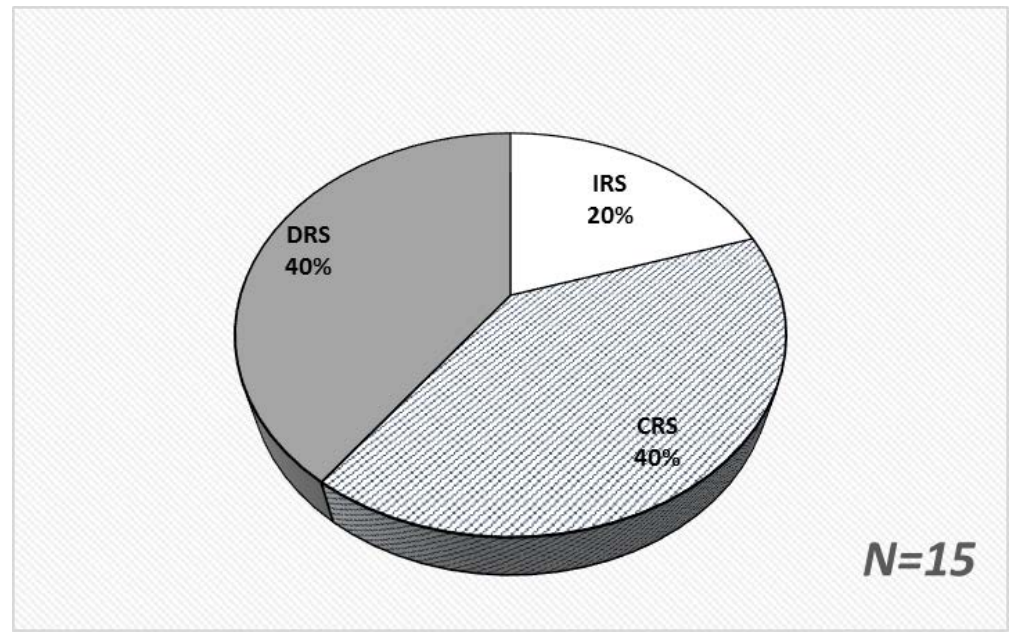

Figure 5: Returns to scale characteristics of studied FPAs (CRS= constant returns to scale, $\mathrm{DRS}=$ decreasing returns to scale, $\mathrm{IRS}=$ increasing returns to scale)

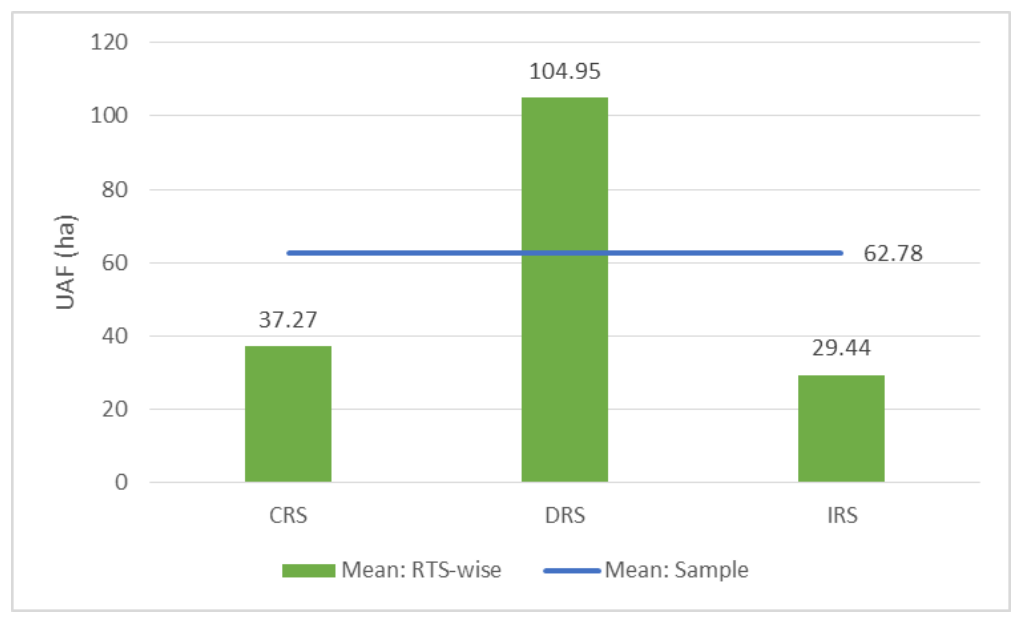

Figure 6: Mean land size of FPAs in terms of RTS characteristics

Internal comparisons of the FPAs: This section will briefly present the FPAs

performance in terms of variations in the organizational composition and mode of aquaculture management outlined in section 2 .

Table 4 shows the mean efficiency scores (percentage) of NFPAs and IFPAs against those of the sample. These scores are plotted in Figure 7. While both groups scored similarly in terms of pure technical and mix efficiency, IFPAs had lower scores in scale efficiency than NFPAs. This lower score ultimately led to their lower than average overall efficiency score (SBM) of $75.96 \%$. In addition, NFPAs also had more efficient units (four) than IFPAs (two). However, Uttompur with the lowest efficiency score of $27.82 \%$ is an IFPA. Probably because of 
this unit the standard deviations of NFPAs are usually higher than those of IFPAs. Regarding IFPAs, it should be noted that, their lower number of efficient units may result from their relatively smaller presence in the sample (five IFPAs to 10 NFPAs) due to their absence outside Daudkandi region.

Table 4: Comparisons of mean efficiency scores between NFPAs and IFPAs with standard deviation (sd) in parenthesis

\begin{tabular}{llll}
\hline & Mean efficiency (\%) & Mean efficiency (\%) & Mean efficiency (\%) \\
& NFPAs (sd) & IFPAs (sd) & Sample (sd) \\
& $\mathbf{n}=\mathbf{1 0}$ & $\mathbf{n}=\mathbf{5}$ & $\mathbf{N}=\mathbf{1 5}$ \\
\hline BCC & $96.17(7.03)$ & $96.45(7.39)$ & $96.26(6.88)$ \\
SE & $90.80(17)$ & $87.26(16.10)$ & $89.60(16.26)$ \\
CCR & $87.32(17.43)$ & $84.16(14.82)$ & $86.26(16.19)$ \\
ME & $89.63(12.42)$ & $90.25(9.38)$ & $89.83(11.15)$ \\
SBM & $78.27(23.54)$ & $75.96(21.18)$ & $77.49(22.12)$ \\
\hline
\end{tabular}

If we draw a comparison between NFPAs and IFPAs of the Daudkandi region, where the IFPAs (five units) have more comparable presence against NFAPs (six units), we can see that IFPAs fared better with respect to number of efficient units- two IFPAs in contrast to only one NFPA. Despite this, on average, NFPAs (average score $82.27 \%$ ) of this site were better than IFPAs (average score 75.96\%). This was caused by the individual scores of FPAs. While the

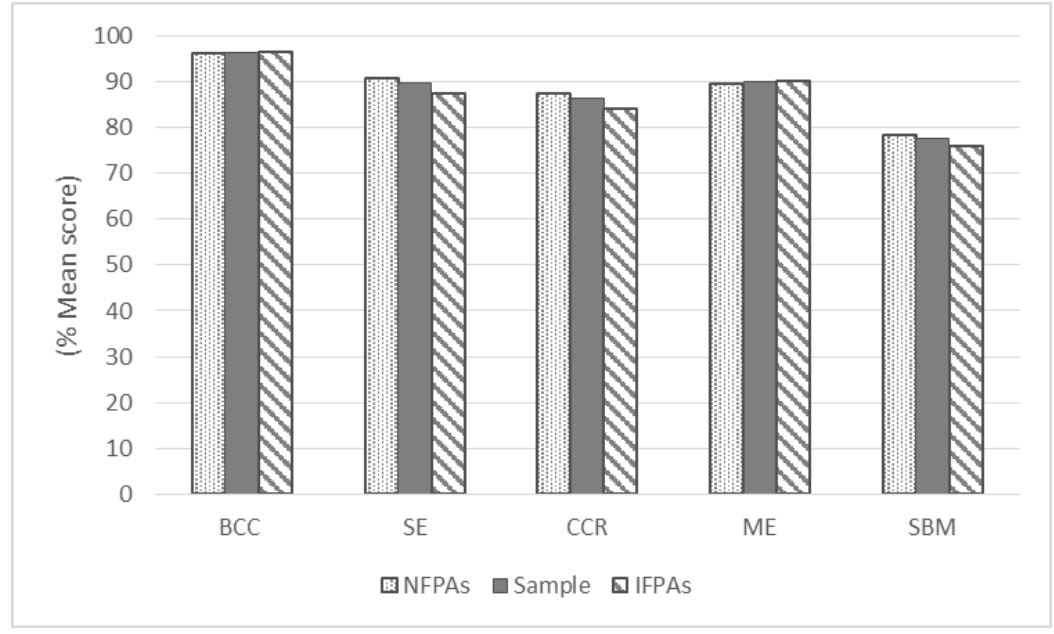

Figure 7: Mean efficiency scores (\%) of NFPAs, the sample \& IFPAs 
inefficient IFPAs (Asia, Charipara and Shishir) of this site scored lower than the sample mean, three inefficient NFPAs (Chargram, Pankowri and Proshanto), out of five, scored above the sample average. Thus, it seemed that although IFPAs of the Daudkandi region had more efficient units, the inefficient units performed significantly poor in our sample.

DEA results also revealed some additional aspects of efficiency within NFPAs, of which all operational units are included in this study. First, out of ten NFPAs in our sample, six are located in the Daudkandi region. In addition, they are also older and larger in terms of fish production than NFPAs of other four sites. However, in our DEA analysis, except Shanto, all NFPAs from the Daudkandi region turned out to be inefficient. By contrast, although we found only one NFPA in each of the other four sites, except Uttompur, other NFPAs showed overall efficiency.

Second, using DEA results we can evaluate the role of NGO in efficient performance of the NFPAs. We have seen that in Daudkandi, out of six NFPAs, only one was overall efficient. Thus, even with above average overall scores $(82.27 \%)$, it is difficult to claim that the participation of NGO result in efficiency in these NFPAs. In addition, the aquaculture operations of NFPAs of the Daudkandi are lease-managed. Under lease arrangement, the FPAs' management committee has almost no control over the aquaculture operation, since its management was transferred to lessee-group. Thus, the NGO, as a member of the FPA management committee, has also very small, if any, control over aquaculture operations. Therefore, while the poor average and individual BCC (Table 2) scores of these NFPAs suggest that the problems lie with the management and operational aspects of aquaculture, they are more likely to be found with the lessees who are now responsible for the aquaculture operations.

On the other hand, out of four NFPAs outside Daudkandi, three were overall efficient. All these NFPAs are self-managed, and thus the involvement of the NGO is more direct in managing their fish culture operations, since they are managed by FPA management committee. 
Moreover, since these NFPAs are relatively new, and therefore its local management committee members were supposedly less experienced, the NGO — having two decades of experience in aquaculture—seemingly provided necessary and important guidelines in managing aquaculture operations, which might contribute in efficient management of aquaculture operation. From this analysis it can be said that while the role of the NGO may be important in the early years of an FPA in terms of providing necessary guideline, it may not be enough in ensuring continuous efficiency of aquaculture operation. It might also be that now the NGO is more experienced and capable in managing aquaculture operations in collaboration with community partners. However, without further research into the nature and extent of NGO involvement in NFPAs, its relationship with FPA efficiency cannot be properly understood.

The IFPAs showed less internal variability in terms of DEA results than NFPAs, as can be found in their standard deviations (Table 4). Moreover, since all the IFPAs were located in the Daudkandi region, the geographical variations in results that were found in the NFPAs, could not be observed in IFPAs. However, in future study, this can be remedied with more focus on and increased number of IFPAs, which were usually overlooked in previous studies.

The comparison between the self-managed and lease-based aquaculture operations in terms of average scores is shown in Table 5 and Figure 8. The DEA results show that the selfmanaged aquaculture operations were better at pure technical efficiency, while lease-based operations were better at scale efficiency. In terms of mix efficiency, their performance was similar. On average, lease-based operations had better overall efficiency scores than self-managed operations, which also had lower than average scores. This is despite the result that, four of the six efficient FPAs were self-managed, while two are lease-managed. The reason for such results can be found if we consider the individual scores of FPAs. While the inefficient self-managed FPAs (Asia, Charipara and Uttompur) scored lower than the sample mean, there were inefficient lease-based operations (Chargram, Pankowri and Proshanto) which scored well above the mean 
but nonetheless failed to reach the efficiency. At the same time, Uttompur which is the most inefficient FPA has self-managed operation. Like NFPAs, because of this FPA, self-managed FPAs showed higher spread of data with higher standard deviations than lease-managed FPAs.

Table 5: Comparisons of mean efficiency scores between self-managed and lease-based aquaculture operation with standard deviation (sd) in parenthesis

\begin{tabular}{llll}
\hline & Mean efficiency (\%) & Mean efficiency (\%) & Mean efficiency (\%) \\
& Self-managed (sd) & lease-based (sd) & Sample (sd) \\
& $\mathbf{n}=\mathbf{7}$ & $\mathbf{n}=\mathbf{8}$ & $\mathbf{N}=\mathbf{1 5}$ \\
\hline BCC & $97.45(6.24)$ & $95.23(7.67)$ & $96.26(6.88)$ \\
SE & $85.91(21.13)$ & $92.97(11.53)$ & $89.60(16.26)$ \\
CCR & $83.72(20.60)$ & $88.54(12.50)$ & $86.26(16.19)$ \\
ME & $89.81(14.24)$ & $89.86(8.64)$ & $89.83(11.15)$ \\
SBM & $75.19(27.47)$ & $79.56(18.21)$ & $77.49(22.12)$ \\
\hline
\end{tabular}

Lease-based FPAs are only found in the Daudkandi region. Among them, two were overall efficient, although their number in the sample was considerably higher than self-managed FPAs (eight against three) in this site. From this it may be assumed that, with more self-managed FPAs in sample, more efficient units might have been found. However, we were reported by the interviewees from this site that nowadays most of the FPAs manage their aquaculture operations

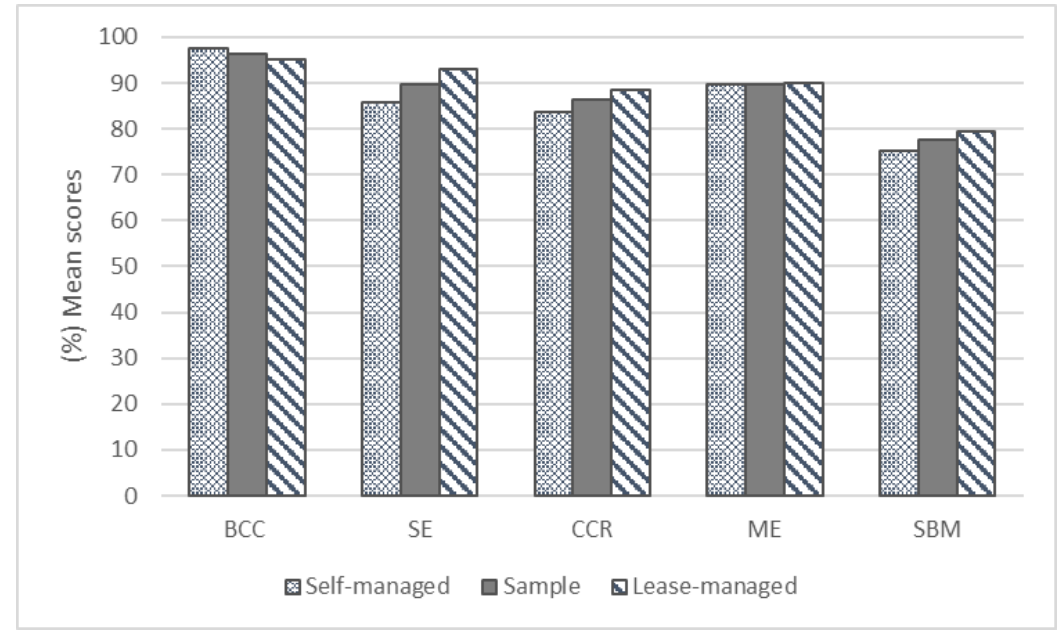

Figure 8: Mean efficiency scores (\%) of Self-managed, the sample \& Lease-managed operations 
under lease-based mechanism, and more are adopting this mode. In spite of reported popularity, the DEA results indicate that lease-based aquaculture operations are not necessarily efficient, since most of lease-based operations remained overall inefficient. Although NGO played leading role in promoting lease-based management of aquaculture in NFPAs of the Daudkandi region, NFPAs outside this site remained under self-management. From DEA results self-management can be justified because most of the FPAs outside Daudkandi are efficient. However, in all these sites the FPA trend is relatively new and continuation of self-managed operations or adoption of lease-based operation depend on future performance of these FPAs, among other factors.

\subsection{Output-oriented efficiency scores of FPAs}

The scores of output-oriented DEA measurements (Table 7) are almost identical to the inputoriented scores. All the efficient and inefficient FPAs of the input-oriented models maintain their status in the output-oriented results. The returns to scale characteristics are also the same. However, in the BCC-O model, the inefficient FPAs display slight differences. This suggests that, given the variable returns to scale feature of BCC model, a few FPAs show minor variations between input utilization and output production. These FPAs (Charipara, Khirai, LKS, and Proshanto) also display slightly different SE-O scores from their SE-I scores, while all other FPAs score identically in both cases. In keeping with DEA principles, CCR-O scores are the same as the CCR-I scores. However, all FPAs have a score of unity in their ME-O scoresindicating no mix inefficiency-because there is only one output (fish sales). By the same token, the SBM-O scores are identical to the CCR-O scores. This indicates that, in the case of singleoutput-producing DMUs, like the studied FPAs, the SBM-O scores reflect only the technical efficiency. Because of these minor differences, the findings from the input-oriented results remain valid for the output-oriented analysis. Thus, we do not repeat them here. 
Table 6: Output oriented efficiency scores of the FPAs

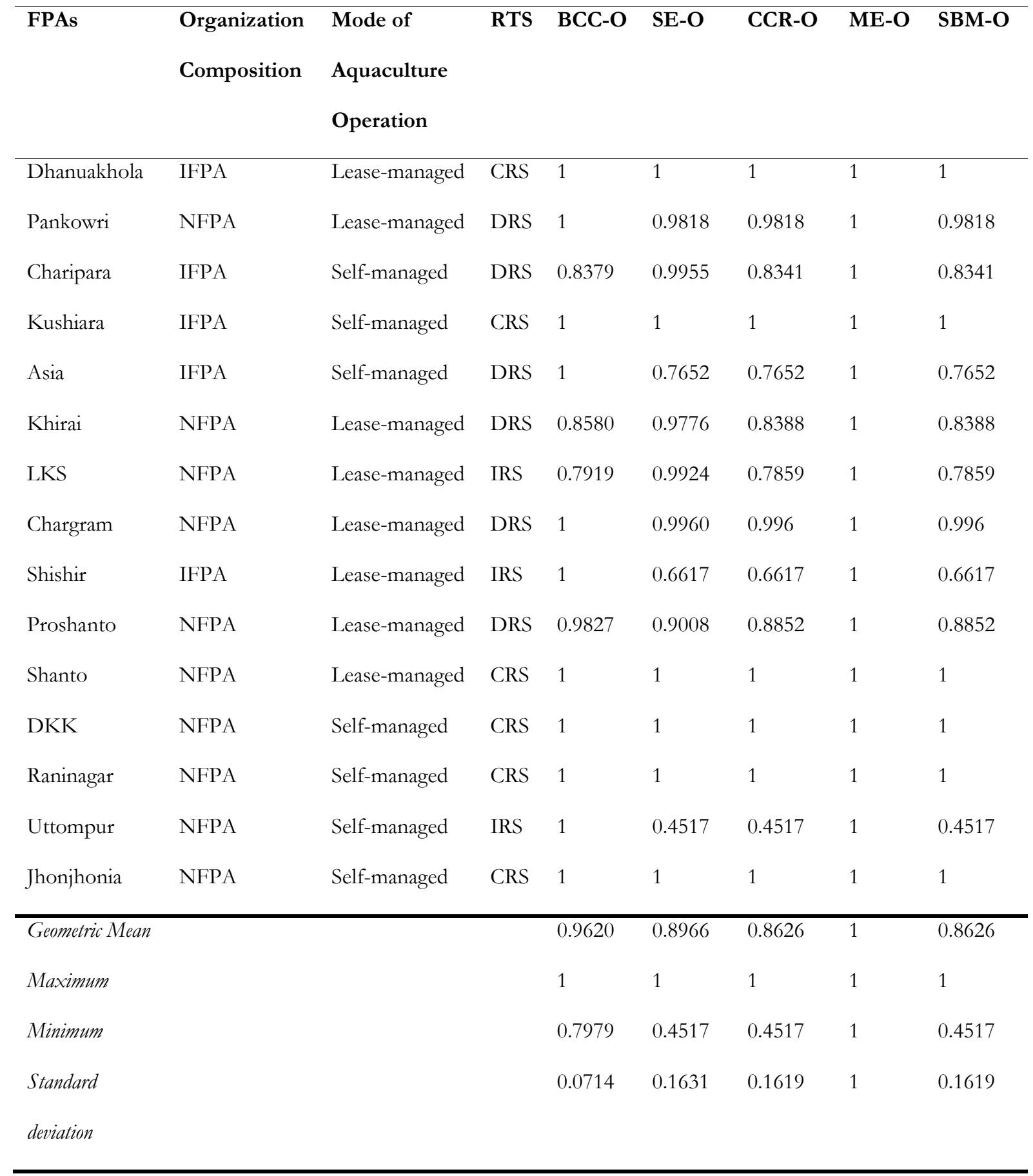

\subsection{Geographical distribution of efficient FPAs}

In addition to the above findings, some further observations can be made regarding the geographical distribution of the efficient FPAs. Although we selected 11 FPAs from the Daudkandi region, considering the high concentration of FPAs in this region, only three of them 
showed overall efficiency. In contrast, of four FPAs selected outside of the Daudkandi region, three showed overall efficient scores. Although the size of fish production is significantly large in the FPAs of the Daudkandi region, they are not efficient in their production. It is clear from our analysis that their inefficiency can be attributed to all three areas of performance-technical, scale, and mix. The technical inefficiency of the FPAs of the Daudkandi region is a little surprising, given their relatively longer experience in aquaculture operations than that of FPAs in the other regions. The DEA results also suggest that these FPAs use more inputs than they need to produce a given level of output, or that they fail to reach the efficient level of output using their inputs. In terms of returns to scale, the existence of decreasing returns in these FPAs may not be completely unexpected, given their attempts to continuously increase the rate of fish production over the years, which resulted in oversized operations. However, the intensive nature of FPAs has been found to be a common concern in previous studies (Mustafa and Brooks, 2009; Sultana, 2012).

A possible factor that may cause efficiency of FPAs outside the Daudkandi region is their age. Since these FPAs are relatively new, they are yet to face the kind of pressure that is faced by the older FPA to maintain annual growth of fish yield. In addition, competition is also low, since there are few FPAs in these sites. This pressure to improve fish yield might lead the older FPAs to use increasing amounts of inputs beyond the level of optimal scale, or to disproportionately increase some inputs in the input mix. In either case such extensive use of inputs didn't result in proportionate output level. In addition, some newer FPAs, like Jhonjhonia, reported that they have input advantages regarding feed, because the floodplain contained sufficient natural feed supply and they did not need a larger amount of supplementary feed. Others reported that there are considerable number of naturally recruited fish, which are not found in the most extensive aquaculture of the Daudkandi region.

\subsection{Additional possible factors explaining inefficiency}


We already mentioned some possible factors, like the role of NGOs as an experienced partner, intensive use of inputs, age of FPAs, etc., that may contribute in the efficiency outcomes of the FPAs. Although further exploration of factors that contributed to the inefficiencies of the FPAs was beyond the scope of the current study, some comments can be made in light of our observations during the field visits.

Among the FPAs, Uttompur showed the lowest overall score. We found that this resulted from the loss of stocked fish during the mid-monsoon of 2015 when floods damaged the embankments that kept the fish within the enclosed area of the floodplain. As a result, a large number of stocked fish were released from the enclosed area. Although such damages caused by flood are not observed in other studied FPAs (where the floodplains are protected by strong earthen embankments), the loss of fish stock due to flood and the related importance of flood pattern and water management infrastructure are cited as important determinants in performance of floodplain aquaculture (Dey et al., 2005; Joffre and Sheriff 2011). It may be noted that Uttompur is also a very new FPA as it was established in 2015. Therefore, the lack of experience of its management committee in terms of predicting and taking necessary precaution against floods, like building strong embankment, may be attributable for such loss. Although the NGO is a partner in this FPA, the failure to predict and prepare for such incident suggests that it may not familiar with all relevant geographical features of this floodplain.

As the studied FPAs are involved in seasonal fish culture operation, period for fish growth, size, density and timing of released fingerlings, quality and quantity of feed and fertilizer, among others, are also of vital importance in determining efficiency of culture activities (Ahmed \& Garnett 2011; Dey et al., 2005; Joffre and Sheriff 2011). The FPAs utilized longer nurture period, released larger fingerlings, as was also common in other floodplain aquaculture (Joffre and Sheriff 2011), and was mostly dependent on supplementary feed. However, day to day operationalization of such practices might vary among FPAs depending on the differences in managerial capacity, styles, technical expertise of managers, along with financial strength of FPA 
or lessees, price, availability of quality inputs. With respect to stocking and feeding practices, some interviewed managers from the Daudkandi region mentioned that overstocking and overfeeding are now increasingly practiced by many managers and cause inefficiency in many FPAs.

At the same time, some managers also cited lack of fish culture related technical knowledge and experience among many managers as possible cause of lower efficiency. We found this especially relevant in terms of lease-based management of aquaculture. The lesseegroup is usually selected through a bidding process, where the highest bidder obtains the lease. This process does not ensure the managerial or technical quality or experience of the lessee, but rather the highest transfer payment to FPAs. Thus, any member of local community with entrepreneurial drive and financial capacity can now take lease of aquaculture operations regardless of their fish farming competence and experience. In few lease-based operations, we were reported that the chief lessee who was supposed to oversee the aquaculture operation remained absence due to his obligation in other professional areas. Since many of lessees are also prominent local traders and merchants, such phenomena are not unusual. Moreover, aquaculture operation is usually leased for two to three years. Such a short-term perspective may not be enough to make the aquaculture operation efficient, as we observed during the field visits that, many lease-based operations failed to make any profit in the first year of their tenure. At the same time, it was reported that by the interviewees that with increasing popularity of lease-based management, many previously better-performing self-managed FPAs are now adopting leasebased operations.

In a few cases, especially IFPAs, we found that the management committees remained unchanged for long time. In absence of changes, inefficiencies and negligence may result in management. We also found deficiencies in keeping adequate records (e.g. simple lapses in book keeping consistencies) resulted in the loss of fish-sales data in one FPA. Finally, a common phenomenon across all FPAs is the lack of specialized learning, professional training and 
background about aquaculture in general and floodplain aquaculture in particular among the participants. Most participants acquire working knowledge through a learning-by-doing process. Like most of the ordinary shareholders, the members of the management committees were previously neither fishermen nor fish farmers by profession.

Thus, in the main, inefficiencies can be attributed to factors, like negligence on the part of the responsible party (e.g. lessees or members of the management committee), inexperienced management (e.g. leasing the aquaculture operation to a lessee-group with little experience in management). However, given the complex process aquaculture management which involves collective action of many stakeholders, there remain other factors the exploration which is out of the scope of present study. Such factors need to be identified and analysed to fully understand their causal relationships with efficiency outcomes.

\section{CONCLUSIONS}

In this study we measured efficiency of collective floodplain aquaculture enterprises that were formed by adopting a similar organizational and management approach. The organizational commonalities can be found in the greater presence of landowners as the participants, and investment-based participation requirement for all members. The management similarities emanated from the role of management committee who preserve the rights to decide upon all aspects and perform all functions related to fish culture operation. Such rights include, but not limited to, the sole control over harvesting. However, within these similarities, we also found two important variations, in some studied FPAs, in terms of (1) organizational composition that resulted from the investment-based participation of the NGO, SHISUK, and (2) mode of managing aquaculture operation that resulted from transferring fish culture rights to lessees by the management committee of FPAs. Thus, we also tried to see whether FPAs with any specific organizational composition and/or management mode showed more efficient performance than other organization type or mode. At the same time, given the role of the NGO in developing this management system, we included all NGO-collaborated FPAs (NFPAs) that were 
operational at the time of study. While previous studies associated this management system solely with Daudkandi region, we included newer NFPAs from other parts of the country-as an indication that the management system has undergone expansion— to examine how these relatively newer FPAs perform. However, the number of NFPAs outside the Daudkandi region is still very small to conclude any widespread trend. Thus, in the sample we considered the existing organizational and operational management variations, geographical distribution, different age and the role of NGO within the studied management system.

We also introduced DEA methodology to measure efficiency of the FPAs of this management system. While a few of our findings corroborated those of previous non-DEA studies, through our analysis we have identified areas and sources of inefficiencies that could not have been identified without applying the DEA models. Our analysis found six FPAs to be efficient in technical, scale and mix categories, thus also overall efficient, out of 15 FPAs selected from five districts. In our sample, NFPAs performed better with four efficient units and better average overall efficiency scores of $78.27 \%$ than independent FPAs (IFPAs) with two efficient units and overall efficiency scores of $75.96 \%$. However, the number of NFPAs is also higher in our sample due to the total absence of IFPAs outside the Daudkandi region. In this site, interestingly, we found two efficient IFPAs (out of five) in contrast to only one efficient NFPA (out of six). However, out of four NFPAs from four other sites, three turned out as efficient. Although the role of NGO seemed important in efficient performance of relatively newer NFPAs of other sites, its role appeared minor in NFPAs of Daudkandi due to their lease-based management of aquaculture operations. With respect to FPAs adopting lease-based operations, we found them having, on average, better overall efficiency scores of $79.56 \%$ but only two efficient units, while self-managed FPAs had lower than average score of $75.19 \%$ but four efficient units. From such results it is not clear whether lease-based mode of aquaculture operation is better than self-managed operations in ensuring efficiency. Thus, from the DEA results, it was not possible to establish any straightforward relation between a particular 
variations-namely organizational composition and mode managing aquaculture operations, and efficiency of aquaculture operations. It should also be noted that, given small sample size, any valid statistical correlation between these internal variations and efficiency is also not possible using the DEA results.

One limitation of DEA methodology is that it requires standardized inputs and outputs across all DMUs. Therefore, any specific input which may be of minor significance for most of the DMUs but be the source of inefficiency in one or two FPAs cannot be included in DEA application. At the same time, the numbers of inputs also impact the efficiency results, especially in cases where sample size is small, as was of this study.

From the inefficiency sources found in DEA analysis, some obvious remedies for inefficiencies can be assumed. The large slacks in UAF may be reduced by allocating the excess area for another use, preferably rice cultivation, the potential for this has been emphasized in some studies (Ahmed et al., 2011). While technically inefficient lease-based operations should focus on improving the managerial and operational aspects by finding better lessees with good track records, the FPAs with a supra-optimal scale should operate at optimal returns to scale. The NGO may play an important role in informing the community practitioners about scale or mix efficiency aspects of aquaculture operations. The local offices of government fishery agencies may also play similar roles.

Given the protein linkage, albeit not necessarily micronutrient linkage (Belton and Thilsted, 2014; Bogard et al., 2015), and the mitigating role of aquaculture in the wake of the sharp decline in capture fishery (Belton et al., 2014), along with FPAs being one of the fastest growing aquaculture niches, it may be time for the government to consider efficiency-related aspects - in addition to the usual growth-related emphasis — in its policy formulation. In addition, aquaculture in rice fields also reported to contribute positively in rice productivity in Bangladesh (Joffre and Sheriff 2011) and in the Daudkandi region by Gregory et al. (2007). However, both these reports are based on anecdotal information provided by farmers. At the 
same time, dealing with inefficiencies may result in better management of the environment as Asche et al. (2009) reported that technical inefficiencies in aquaculture practices can affect the overall environment. Nonetheless, any policy should be judicious enough not to be too restrictive on any specific sector as recommended by Hernandez et al. (2017), acknowledging the indirect roles of government policies in the overall growth of the aquaculture sector in Bangladesh.

It may be noted that, although we used the data from the financial reports of the FPAs, we found that, except one, no other FPAs conducted any external auditing of their reports. The practice of external auditing will increase the reliability of the financial reports and bring the reporting practices in line with accepted accounting practices. In addition, and more importantly, making such audited reports easily available to all ordinary shareholders will increase trust and confidence among them, and make them informed about their investment and its outcomes, since most of them do not usually participate in management of the FPA operation. In addition, such audited reports will also assist any external interested party, like government, development agencies, researchers, among others, to learn reliability about the various aspects of the FPAs and develop cooperation and collaboration with them.

While a few of our findings corroborated those of previous non-DEA studies, through our analysis we have identified areas and sources of inefficiencies that could not have been identified without applying the DEA models. Although small, our sample included all sites where this management system was found, the oldest and newest FPAs and considered internal variations in terms of organizational composition and modes of aquaculture operation, role of NGO. Nonetheless, given the small sample size confined to a particular FPA management system, we remain cautious in claiming that the results are representative of the country-wide trend of FPAs. Not only are there various types of fisheries and aquaculture enterprises practiced in various floodplains with different management approaches, but there is also involvement of many NGOs providing diverse types of assistance in many of them (Dey et al., 2013; Haque et 
al., 2011; Khan 2015; Sultana, 2012; Thompson et al., 2003 \& 2005). To gain a country-wide perspective of the efficiency of fish production from floodplains, it is necessary to conduct a nationwide representative study, since different management approaches may effect different outcomes. Nonetheless, this study remains valid for the studied management system, providing a framework for and highlighting aspects to be investigated in future research on FPAs in Bangladesh at a national level.

\section{Acknowledgments}

The authors would like to express their gratitude towards the NGO staffs, along with the staffs of all FPAs, for their wholehearted assistance during the collection of and follow-up inquiries about the data. 


\section{References}

Ahmed, M. N. (1999). Fingerling stocking in openwaters. In H.A.J. Middendorp, P.M.

Thompson and R.S. Pomeroy (eds.) Sustainable Inland Fisheries Management in Bangladesh. ICLARM Conference Proceedings 58.

Ahmed, N., Zander, K. K., \& Garnett, S. T. (2011). Socioeconomic aspects of rice-fish farming in Bangladesh: opportunities, challenges and production efficiency. Australian Journal of Agricultural and Resource Economics, 55(2), 199-219.

Akter, M., Afroz, T., \& Mustafa, M. G. (2015). Aquaculture practices in two seasonal floodplains of Bangladesh. Bangladesh Journal of Zoology, 41(2), 217-228.

Alam, F. (2011). Measuring technical, allocative and cost efficiency of pangas (Pangasius hypophthalmus: Sauvage 1878) fish farmers of Bangladesh. Aquaculture Research, 42(10), $1487-$ 1500.

Alam, F. M., \& Murshed-e-Jahan, K. (2008). Resource allocation efficiency of the prawn-carp farmers of Bangladesh. Aquaculture Economics \& Management, 12(3), 188-206.

Arjumanara, L., Alam, M. F., Rahman, M. M., \& Jabbar, M. A. (2004). Yield gaps, production losses and technical efficiency of selected groups of fish farmers in Bangladesh. Indian Journal of Agricultural Economics, 59(4), 808-818.

Asche, F., Guttormsen, A. G., \& Nielsen, R. (2013). Future challenges for the maturing Norwegian salmon aquaculture industry: An analysis of total factor productivity change from 1996 to 2008. Aquaculture, 396, 43-50.

Asche, F., Roll, K. H., \& Tveteras, R. (2009). Economic inefficiency and environmental impact: An application to aquaculture production. Journal of Environmental Economics and Management, 58(1), 93-105. 
Banker, R. D., Charnes, A., \& Cooper, W. W. (1984). Some models for estimating technical and scale inefficiencies in data envelopment analysis. Management science, 30(9), 1078-1092.

Bayazid, Y. (2016). The Daudkandi model of community floodplain aquaculture in Bangladesh: a case for Ostrom's design principles. International Journal of the Commons, 10 (2), 854-877. DOI: http://doi.org/10.18352/ijc.511

Bayazid, Y., Miyanishi, T., Umetsu, C., \& Hamasaki, H. (2018). The evolution of a floodplain aquaculture management system in Bangladesh. International Journal of the Commons, 12 (1), 249-277. DOI: http://doi.org/10.18352/ijc.811

Belton, B., Karim, M., Thilsted, S., Collis, W., \& Phillips, M. (2011). Review of aquaculture and fish consumption in Bangladesh. The WorldFish Center Studies and Reviews 2011-53, 76p. Penang, Malaysia

Belton, B., van Asseldonk, I. J. M., \& Thilsted, S. H. (2014). Faltering fisheries and ascendant aquaculture: Implications for food and nutrition security in Bangladesh. Food Policy, 44, 77-87.

Belton, B., \& Thilsted, S. H. (2014). Fisheries in transition: Food and nutrition security implications for the global South. Global Food Security, 3(1), 59-66.

Bogard, J. R., Thilsted, S. H., Marks, G. C., Wahab, M. A., Hossain, M. A., Jakobsen, J., \& Stangoulis, J. (2015). Nutrient composition of important fish species in Bangladesh and potential contribution to recommended nutrient intakes. Journal of Food Composition and Analysis, 42, 120-133.

Charnes, A., Cooper, W. W., \& Rhodes, E. (1978). Measuring the efficiency of decision making units. European journal of operational research, 2(6), 429-444. 
Charnes, A., Cooper, W. W., \& Rhodes, E. (1981). Evaluating program and managerial efficiency: an application of data envelopment analysis to program follow through. Management science, 27(6), 668-697.

Coelli, T. J., Rao, D. S. P., O'Donnell, C. J., \& Battese, G. E. (2005). An introduction to efficiency and productivity analysis. Springer Science \& Business Media.

Cooper, W. W., \& Seiford, L. M. Tone., K. (2007). Data Envelopment Analysis A Comprehensive Text with Models, Applications, References and DEA-Solver Software. Springer, ISBN, 387452818, 490.

Dey, M. M., \& Prein, M. (2003). Participatory research at landscape level: flood-prone ecosystems in Bangladesh and Vietnam. . In: Pound B, Snapp S, McDougall C, Braun A (eds). Managing natural resources for sustainable livelihoods: uniting science and participation. Earthscan and IDRC, London, 223-225.

Dey, M. M., Prein, M., Mahfuzul Haque, A. B. M., Sultana, P., Cong Dan, N., \& Van Hao, N. (2005). Economic feasibility of community-based fish culture in seasonally flooded rice fields in Bangladesh and Vietnam. Aquaculture Economics \& Management, 9(1-2), 65-88.

Dey, M. M., Spielman, D. J., Haque, A. M., Rahman, M. S., \& Valmonte-Santos, R. (2013). Change and diversity in smallholder rice-fish systems: Recent evidence and policy lessons from Bangladesh. Food Policy, 43, 108-117.

Farrell, M. J. (1957). The measurement of productive efficiency. Journal of the Royal Statistical Society. Series A (General), 120(3), 253-290.

FRSS (2013). Fishery Statistical Yearbook of Bangladesh 2011-2012. Fisheries Resources Survey System, Department of Fisheries (DOF), Ministry of Fisheries and Livestock, Dhaka, Bangladesh. 
FRSS (2017). Fishery Statistical Yearbook of Bangladesh 2014-2015. Fisheries Resources Survey System, Department of Fisheries (DOF), Ministry of Fisheries and Livestock, Dhaka, Bangladesh.

Gregory, R., Toufique, K. A., \& Nuruzzaman, M. (2007). Common interests, private gains: a study of co-operative floodplain aquaculture. Paper Presented at the CBFM-2 International Conference on Community Based Approaches to Fisheries Management, 6-7 March 2007, Dhaka, Bangladesh.

Haque, A. M., Visser, L. E., \& Dey, M. M. (2011). Institutional arrangements in seasonal floodplain management under community-based aquaculture in Bangladesh. Asian Journal of Agriculture and Development, 8(1), 1.

Hernandez, R., Belton, B., Reardon, T., Hu, C., Zhang, X., \& Ahmed, A. (2017). The "quiet revolution" in the aquaculture value chain in Bangladesh. Aquaculture. http://dx.doi.org/10.1016/j.aquaculture.2017.06.006

Iliyasu, A., Mohamed, Z. A., Ismail, M. M., Abdullah, A. M., Kamarudin, S. M., \& Mazuki, H. (2014). A review of production frontier research in aquaculture (2001-2011). Aquaculture Economics \& Management, 18(3), 221-247.

Iliyasu, A., Mohamed, Z. A., \& Terano, R. (2016). Comparative analysis of technical efficiency for different production culture systems and species of freshwater aquaculture in Peninsular Malaysia. Aquaculture Reports, 3, 51-57.

Islam, M. Z. (1999). Enhancement of floodplain fisheries: experience of the Third Fisheries Project. In H.A.J. Middendorp, P.M. Thompson and R.S. Pomeroy (eds.) Sustainable Inland Fisheries Management in Bangladesh. ICLARM Conference Proceedings 58.

Joffre, O. M., \& Sheriff, N. (2011). Conditions for collective action: understanding factors supporting and constraining community-based fish culture in Bangladesh, Cambodia and 
Vietnam. WorldFish Center Studies and Reviews 2011-21. The WorldFish Center, Penang, Malaysia. 46 p.

Khan, M. (2015). The Political Economy of Community-Based Fisheries Management in Bangladesh.

http://eprints.soas.ac.uk/19619/1/The\%20Political\%20Economy\%20of\%20CommunityBased\%20Fisheries\%20in\%20Bangladesh.pdf. Retrieved on February 18, 2016

Mustafa, M. G., \& Brooks, A. C. (2009). A comparative study of two seasonal floodplain aquaculture systems in Bangladesh. Water policy, 11(S1), 69-79.

Seiford, L. M., \& Thrall, R. M. (1990). Recent developments in DEA: the mathematical programming approach to frontier analysis. Journal of econometrics, 46(1-2), 7-38.

Sharma, K. R., \& Leung, P. (2003). A review of production frontier analysis for aquaculture management. Aquaculture Economics \& Management, 7(1-2), 15-34.

Sharma, K. R., Leung, P., Chen, H., \& Peterson, A. (1999). Economic efficiency and optimum stocking densities in fish polyculture: an application of data envelopment analysis (DEA) to Chinese fish farms. Aquaculture, 180(3), 207-221.

Sultana, P. (2012). Implications of floodplain aquaculture enclosure. Journal of Environmental Planning and Management, 55(9), 1159-1174.

Thompson, P. M., Sultana, P., \& Islam, N. (2003). Lessons from community based management of floodplain fisheries in Bangladesh. Journal of environmental management, 69(3), 307-321.

Tone, K. (2001). A slacks-based measure of efficiency in data envelopment analysis. European journal of operational research, 130(3), 498-509.

Toufique, K. A., \& Gregory, R. (2008). Common waters and private lands: distributional impacts of floodplain aquaculture in Bangladesh. Food policy, 33(6), 587-594. 
Thompson, P. M., Sultana, P., \& Khan, A. K. F. (2005). Aquaculture extension impacts in

Bangladesh: a case study from Kapasia, Gazipur (Vol. 1717). WorldFish.

Vázquez-Rowe, I., Iribarren, D., Moreira, M. T., \& Feijoo, G. (2010). Combined application of

life cycle assessment and data envelopment analysis as a methodological approach for the

assessment of fisheries. The International Journal of Life Cycle Assessment, 15(3), 272-283.

\footnotetext{
${ }^{1}$ Shikhya, Shastha, Unnayan Karjakram in Bengali, which can be translated into English as Education, Health and Development Programme.

${ }^{2}$ Payment of land rent is practiced in all FPAs, except one (Dhanuakhola). However, the mode of payment of land rent seems non-conventional. Although it is paid to the landowners because of their ownership of lands, it is not paid in advance to the landowners and does not depend on any rate fixed at the beginning of fish culture operation. Rather, it is paid as a portion of net return or profit and calculated as percentage of profit. Thus, its payment is contingent upon the making of profit. If an FPA cannot make profit it does not pay land rent to the landowners. In the early years of their operations, when many FPAs failed to make profit, such land rent was not paid to landowners. However, as most of the FPAs are now profitable, land rent is paid to all landowners regardless of being a participant or not of the FPAs. It may be added that, this way of paying land rent from the profit might affect the management of aquaculture operation in the same manner as does the possibility of earning dividend from profit.

${ }^{3}$ It may seem that land rent which is paid to the landowners in most FPAs can be considered as an input for calculating land's contribution in fish production. However, as we mentioned in note 2 , land rent is paid after fish sales are completed, and only if profits can be generated from these fish sales. In the FPA (Uttompur) which failed to make profit, we did not find payment of any land rent. However, in such an FPA land's contribution in fish production remains. Thus, land rent cannot represent land's contribution in fish production
} 